\title{
RANCANG BANGUN DATABASE DUA ARAH \\ DENGAN KENDALI RASPBERRY PI PADA INTEGRASI SISTEM INFORMASI GEOGRAFIS PENYAKIT MENULAR
}

\author{
Angga Prasetyo \\ Fakultas Teknik, Program Studi Teknik Informatika \\ Universitas Muhammadiyah Ponorogo \\ Email: uzhumaki07@gmail.com
}

\begin{abstract}
ABSTRAK
Puskesmas sebagai unit kesehatan tingkat pertama memiliki tugas pokok yaitu pengobatan, perawatan kesehatan, kesehatan lingkungan, membina kesehatan ibu dan anak, pencegahan penyakit menular, pencatatan dan pelaporan. Dari keseluruhan tugas tampaknya tidak seluruhnya digarap oleh puskesmas terutama pencatatan dan pelaporan untuk pencegahan penyakit menular serta pola penyebarannya. untuk mengawasi dan mengendalikan perencananan program kesehatan termasuk penekanan penyebaran penyakit menular, puskesmas belum memiliki alat bantu yang terintegrasi satu atap secara real time dengan dinas kesehatan, untuk itu dibutuhkan sistem informasi geografis (SIG) untuk memvisualisasikan data penyakit menular, hal ini juga perlu ditunjang perangkat yang optimal dengan biaya yang murah dengan menggunakan raspberry pi sebagai kendali otomasi server data dalam replikasi. Proses memanfaatkan replikasi database dua arah menggunakan dua server dengan server satu sebagai master sedangkan server lainnya berfungsi sebagai slave. Hasil pengujian replikasi pada transaction rate untuk meminimalkan antrian data node 1 pada nilai 1,99/detik setiap transaksi data, node 2 nilai 2,02/detik, sedangkan balancer dengan nilai 1,91/detik, sedangkan response time atau kecepatan replikasi database dalam menangkap dan mengirimkan data sangat efektif, pada node $10,33 / \mathrm{s}$ untuk kecepatan proses, node 2 dengan waktu $0,01 / \mathrm{s}$, dan balancer $0,13 / \mathrm{s}$.
\end{abstract}

Kata kunci: puskesmas, replikasi database dua arah, penyakit menular, dinas kesehatan, sistem informasi geografis (SIG).

\begin{abstract}
People health clinic as the first level of the health unit has the main task, namely treatment, health care, environmental health, maternal and child health fostering, infectious disease prevention, record keeping and reporting. Of the overall task seems not entirely worked out by the health center primarily for recording and reporting to the prevention of infectious diseases and patterns of spread. to supervise and planning control health programs including suppression of spread of infectious diseases, health centers do not have the tools that are integrated with the one roof in real time with the health department, for it takes a geographic information system (GIS) to visualize the data of infectious diseases, it also needs to be supported device optimal at low cost by using raspberry pi as automation control server in the replication of data. The process utilizes bi-directional database replication using two servers with one server as the master, while the other server is functioning as a slave. The test results on the transaction replication rate to minimize data queue node 1 to the value of 1.99 / sec each transaction of data, node 2 value of 2.02/s, while a balancer with a value of 1.91 / sec, while the response time or the speed of database replication in capture and transmit data very effectively, at node $10.33 / \mathrm{s}$ to speed the process, node 2 with a time of $0.01 /$ s, and a balancer $0.1 /$ s.
\end{abstract}

Keywords: puskesmas, bi-directional database replication, infectious diseases, public health office, geographic information system (SIG).

\section{PENDAHULUAN}

Pusat kesehatan masyarakat (puskesmas) merupakan salah satu bentuk pelayanan kesehatan yang diberikan pemerintah yang tertuang pada peraturan menteri kesehatan No 75/2014/Bab I/Pasal 1 disebutkan puskesmas adalah fasilitas pelayanan kesehatan yang menyelenggarakan upaya kesehatan masyarakat dan kesehatan perseorangan tingkat pertama dengan mengupayakan promotif dan preventif untuk mencapai derajat kesehatan masyarakat setinggi-tingginya. Puskesmas sebagai unit kesehatan tingkat pertama yang bersentuhan langsung dengan masyarakat memiliki tugas pokok yaitu pengobatan, perawatan kesehatan, kesehatan lingkungan, membina kesehatan ibu dan anak, pencegahan penyakit 
menular, pencatatan dan pelaporan. Dari keseluruhan tugas tampaknya tidak seluruhnya digarap oleh puskesmas terutama pencatatan dan pelaporan untuk pencegahan penyakit menular serta pola penyebarannya. Untuk mengetahui pola penyebaran penyakit menular dibutuhkan suatu integrasi data dan informasi yang real time agar proses penanganan serta antisipasi tidak lamban.

Untuk mengintegrasikan data yang real time, antara puskesmas dan dinas kesehatan dalam kegiatan pencegahan serta penanggulangan penyakit menular diperlukan strategi dengan memanfaatkan replikasi database dua arah. Replikasi dua arah adalah replikasi basis data menggunakan dua server dengan server satu sebagai master sedangkan server lainnya berfungsi sebagai slave, dimana saat master melakukan perubahan data secara otomatis slave akan melakukan perubahan sesuai data yang diubah pada master begitu pula sebaliknya[7]. Proses otomasi membutuhkan server data yang harus dibangun tetapi untuk merealisasikan membutuhkan investasi sangat mahal untuk itu dibutuhkan perangkat murah dan memiliki performa tinggi dengan Raspberry pi.

Dalam proses pengambilan keputusan untuk pencegahan penyebaran penyakit menular oleh dinas kesehatan dibutuhkan visualisasi data dalam bentuk pemetaan pola sebaran penyakit menular dengan memanfaatkan sistem informasi geografis (SIG). Menurut [9] Sistem informasi geografis (SIG) adalah sistem yang berdasarkan data keruangan dan merepresentasikan dalam bentuk obyek di bumi, dalam SIG sendiri terdapat teknologi informasi yang merupakan perangkat dalam menganalisa data, menyajikan data secara terkomputerisasi. Dengan pola SIG sebagai pemetaan sebaran penyakit menular serta replikasi dua arah untuk sinkronisasi data antara puskesmas dan dinas kesehatan diharapkan dapat menjadi surveilan dalam proses antisipasi pencegahan penyebaran penyakit menular yang real time.

Sinkronisasi adalah proses penyesuaian data terhadap skala waktu dari proses osilasi yang terjadi antara proses osilasi tersebut [1]. Pada dasarnya sinkronisasi terdiri dari dua jenis yaitu one-way file syncrhronization (sinkronisasi satu arah) dimana file-file yang telah mengalami perubahan pada bagian pusat (source) akan dibuat salinannya dan dipindah ke lokasi targetnya. Pada one-way file synchronization ini, tidak ada file dari target yang akan menuju ke bagian source. Sedangkan pada jenis yang kedua, two-way file syncrhonization (sinkronisasi 2 arah) proses pembuatan salinan dan pemindahannya dapat berjalan 2 arah baik dari source ke target maupun sebaliknya.

Replikasi adalah suatu teknik untuk melakukan kopi dan pendistribusian data dan objek-objek database dari satu database ke database lain dan melaksanakan sinkronisasi antara database sehingga konsistensi data dapat terjamin [3]. Dengan menggunakan teknik replikasi ini, data dapat didistribusikan ke lokasi yang berbeda melalui koneksi jaringan lokal maupun internet. Proses sinkronisasi atau dikenal dengan real time replication dapat dilakukan jika tidak ada toleransi data yang hilang atau perbedaan data, antara data di site sekunder harus sesuai dengan site utama [4] seperti yang ditunjukkan pada Gambar 1.

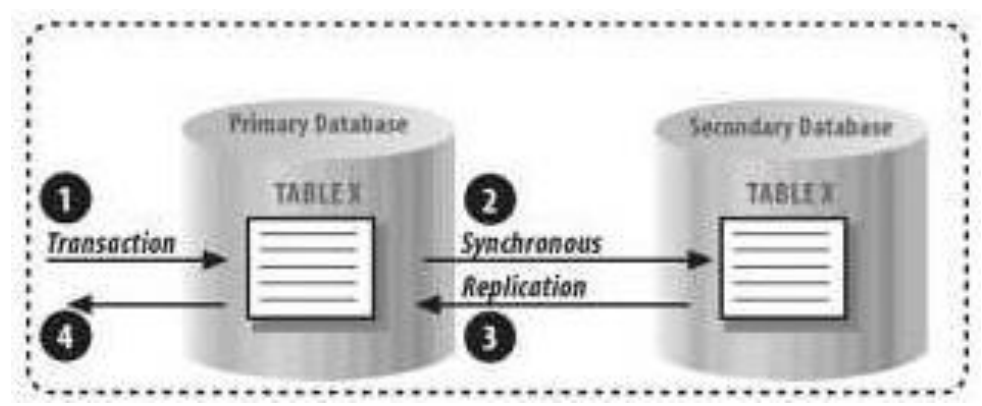

Gambar 1. Proses Sinkronisasi Replikasi

Proses replikasi dari satu database ke database lain pada server yang berbeda menimbulkan beban yang sangat tinggi sehingga dibutuhkan penyeimbang atau dikenal load balancing. Load balancing merupakan kemampuan untuk mentransfer setiap bagian dari proses untuk permintaan sistem utama ke sistem independen lainnya yang akan ditangani secara bersamaan [8]. Terdapat beberapa macam algorima load balancing terdiri dari:

1) Random allocation

Dalam random allocation proses HTTP ditugaskan ke server dengan memilih secara acak diantara kelompok server [6]. Pada kondisi ini, salah satu server mungkin dapat ditugaskan mengeksekusi proses permintaan dengan membagi beban performa server.

2) Round robin

Kondisi lainnya menurut [2], bahwa suatu load balancing beroperasi menggunakan round robin membuat internal counter dari backend yang terakhir digunakan, dan menggunakan pilihan berikutnya dari daftar berurutan semua backend yang diketahui. Ketika setiap permintaan tiba, 
backend berikutnya dipilih dan counter akan bertambah.

Pada penelitian ini untuk menguji kelayakan replikasi dan proses load balancing maka dibutuhkan perangkat yang fleksibel dan murah yaitu raspberry pi [5], menyatakan raspberry pi merupakan komputer mikro dengan ukuran kartu kredit yang memiliki Single on Chip Broadcom 2835 mencakup memori hingga $1 \mathrm{GHz}$ hanya membutuhkan daya 3,5 watt. Perangkat ini nantinya akan digunakan sebagai proses otomasi sistem infromasi geografis penyakit menular yang berada di puskesmas.

Sistem Informasi Geografis (SIG) / Geographic Information System (GIS) adalah suatu sistem informasi berbasis komputer, yang digunakan untuk memproses data spasial yang ber-georeferensi (berupa detail, fakta, kondisi) yang disimpan dalam suatu basis data dan berhubungan dengan persoalan serta keadaan dunia nyata (real world). Manfaat SIG secara umum memberikan informasi yang mendekati kondisi dunia nyata, memprediksi suatu hasil dan perencanaan strategis seperti ditunjukkan pada Gambar 2 .

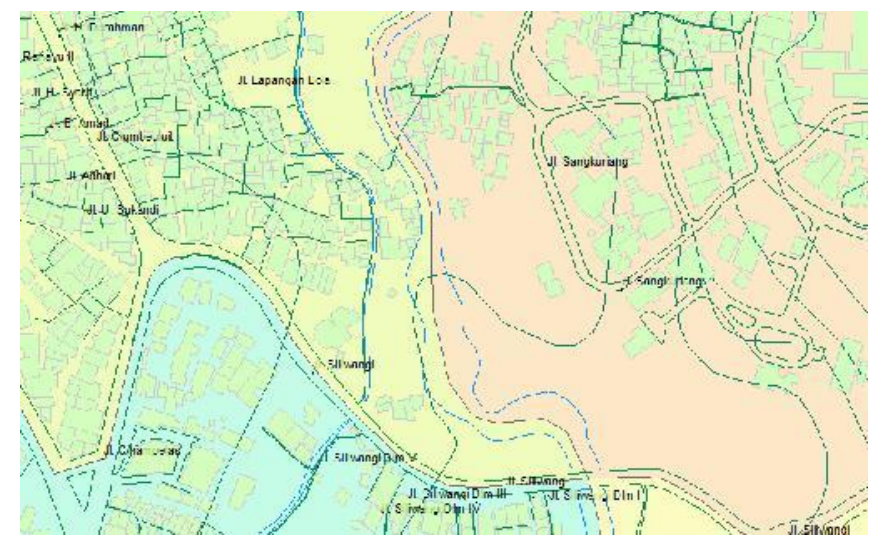

Gambar 2. Model Peta Vektor Surveilan [9]

\section{METODOLOGI PENELITIAN}

Penelitian ini menggunakan pendekatan meliputi library research dan field research, untuk mendesain pola sinkronisasi. Proses ini merupakan kegiatan untuk mengenali lebih lanjut tentang obyek penelitian beserta lingkungan dalam rangka mendalami situasi dan kondisi, dari sinkronisasi dan integrasi yang akan dikembangkan. Studi pendahuluan dilakukan dengan mengumpulkan data uji beserta pola arsitektur pada SIG dan server database.

\subsection{Perancangan Topologi Replikasi}

Proses ini menitikberatkan pada proses dilakukan pengujian dari integrasi replikasi database pada sistem informasi geofrafis penyakit menular, konsep sinkronisasi dan integrasi data dan keberadaan data kesehatan akan ditanamkan pada webserver, dengan memberikan alamat address virtual pada perangkat raspberry pi yang menggunakan algoritma random pada masing- masing unit surveilans dengan dinas kesehatan.

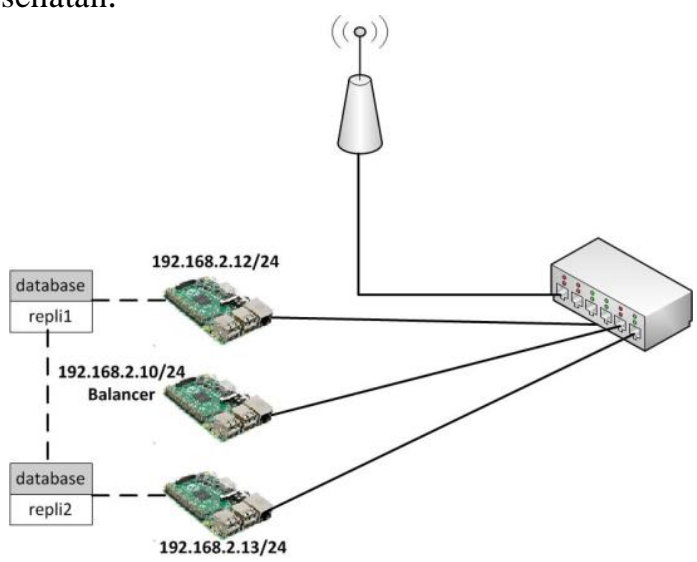

Gambar 3. Model Arsitektur Replikasi Database Dua Arah Pada Raspberry Pi 
Proses replikasi yang ditunjukkan pada topologi Gambar 3, lebih mengarah dalam hal eksplorasi arsitektur dengan tujuan memperoleh avabilitas performa dari proses load balancing pada replikasi database. Sehingga hasil akhir analisis dapat menjadi suatu model dalam pengelolaan database.

\section{HASIL PENELITIAN DAN PEMBAHASAN}

Proses pengujian dilakukan dengan membangun replikasi dua arah pada database sistem informasi geografis penyakit menular, dengan menghubungkan slave IO running master berstatus yes pada setiap node di raspberry pi seperti ditunjukkan pada Gambar 4.

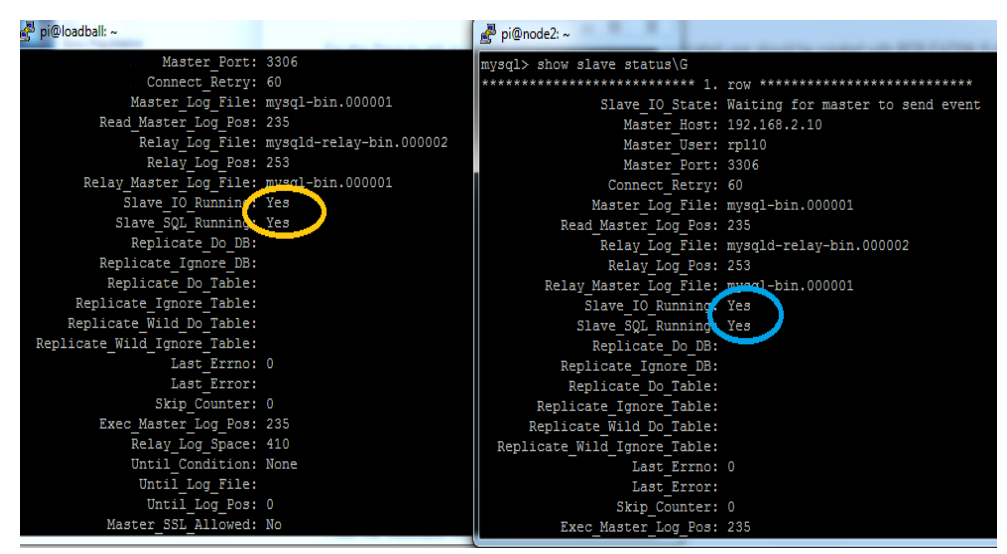

Gambar 4. Perancangan Replikasi Pada Slave Status

\subsection{Pengujian Kinerja Replikasi}

Hasil peracangan perangkat lunak SIG dilakukan proses input testing di database dengan data surveilan seperti ditunjukkan Gambar 5. Penyimpanan database SIG yang telah dibangun di puskesmas akan dilakukan pengujian, terdiri dari proses otomasi database tanpa replikasi serta dengan menggunakan replikasi dua arah pada perangkat raspberry pi.

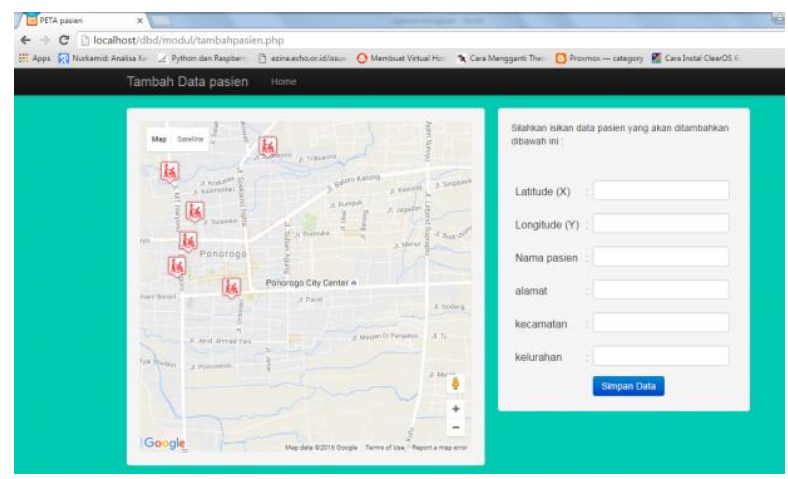

Gambar 5. Tampilan Form Input Data Surveilan Pada SIG

Proses pengujian database yang terintegrasi pada sistem informasi geografis, tanpa menggunakan replikasi, pada masing-masing node raspberry pi menunjukan proses transaction rate node 1 pada nilai $0,7 /$ detik setiap transaksi data dan node 2 pada nilai 0,83 /detik setiap transaksi data, sedangkan response time node 1 dengan waktu 0,9 s dan node 2 dengan waktu 0,8 s. untuk keseluruhan hasil proses dapat dilihat pada Tabel 1. 
Tabel 1. Kinerja database tanpa replikasi

\begin{tabular}{lcc}
\hline \multicolumn{1}{c}{ Raspberry pi } & node1 (192.168.2.12) & node2 (192.168.2.13) \\
\hline transaction (hits) & 577 & 611 \\
availability (\%) & 100 & 100 \\
elapses time & 502,3 & 502,9 \\
Data transferred $(M B)$ & 0,9 & 0,89 \\
Response time $(s)$ & 0,9 & 0,8 \\
Transaction rate $($ trans $/ s)$ & 0,7 & 0,83 \\
Troughput $(M B / s)$ & 0 & 0 \\
concurrency & 0,1 & 0,01 \\
succesfull transaction $(q u e r y)$ & 599 & 570 \\
failed transaction $(q u e r y)$ & 0 & 0 \\
Longest transaction $(s)$ & 0,02 & 0,01 \\
shortest transaction $(\mathrm{s})$ & 0 & 0
\end{tabular}

Sedangkan pengujian database menggunakan replikasi, diperoleh proses transaction rate node 1 pada nilai 1,99/detik setiap transaksi data dan node 2 pada nilai 2,02/detik setiap transaksi data, sedangkan pada balancer berada pada nilai 1,91/detik transaksi data. Aktivitas kecepatan proses replikasi pada database berkaitan dengan response time, pada node 1 dengan waktu 0,33/s untuk kecepatan proses, node 2 dengan waktu $0,01 / \mathrm{s}$ dan balancer $0,13 / \mathrm{s}$ untuk setiap prosesnya. Untuk keseluruhan hasil proses pengujian dapat dilihat pada Tabel 2.

Tabel 2. Kinerja database dengan replikasi

\begin{tabular}{lccc}
\hline \multicolumn{1}{c}{ Raspberry $\mathbf{p i}$} & node1(192.168.2.12) & node2(192.168.2.13) & Balancer(192.168.2.10) \\
\hline transaction $($ hits $)$ & 599 & 606 & 572 \\
availability $(\%)$ & 100 & 100 & 100 \\
elapsed time $(s)$ & 299,8 & 299,89 & 299,63 \\
Data transferred $(M B)$ & 0,91 & 0,94 & 0,89 \\
Response time $(s)$ & 0,03 & 0,01 & 0,13 \\
Transaction rate $($ trans $/ s)$ & 1,99 & 2,02 & 1,91 \\
Troughput $(M B / s)$ & 0 & 0 & 0 \\
concurrency & 0,01 & 0,01 & 0,25 \\
succesfull transaction & 588 & 609 & 577 \\
(query) & & & \\
failed transaction $(q u e r y)$ & 0 & 0 & 0 \\
Longest transaction $(s)$ & 0,02 & 0,01 & 6
\end{tabular}

Dari hasil pengujian proses penggunaan replikasi database yang ditanamkan pada sistem informasi geografis sangat efektif, hal ini ditunjukkan bahwa seluruh proses data transaction rate di node 1 , node 2 , dengan menambahkan balancer mampu melakukan aktivitas dengan beban kerja yang sangat tinggi sehingga antrian data dapat diminimalkan, seperti ditunjukkan pada Gambar 6.

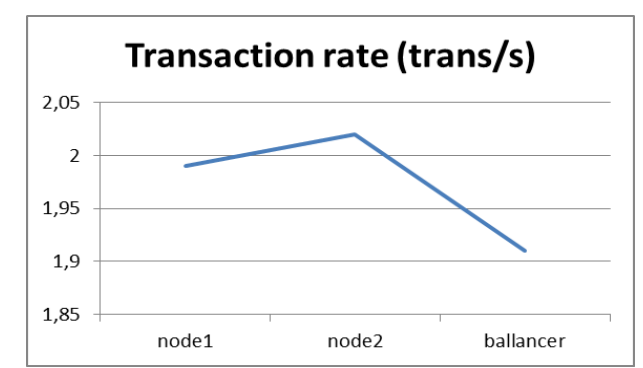

Gambar 6. Transaction Rate Dari Seluruh Node

Sedangkan proses hubungan kecepatan atau response time dalam replikasi database node 1 dan node 2 sistem informasi geografis dengan menambahkan balancer maka diperoleh pembagian perfoma kinerja setiap node akan semakin cepat dalam setiap detik pemrosesan data, seperti ditunjukkan pada Gambar 7 


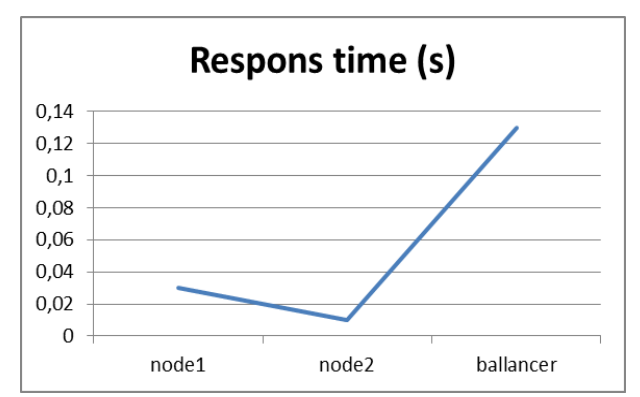

Gambar 7. Response Time Pada Seluruh Node Dan Balancer

\section{KESIMPULAN}

Dari keseluruhan proses pengujian dapat disimpulkan bahwa:

1) Proses replikasi dua arah database yang terintegrasi pada sistem informasi geografis, dengan menambahkan load balancer, diperoleh transaction rate data node 1 pada nilai 1,99/detik setiap transaksi data, node 2 pada nilai 2,02/detik, hal ini dapat meminimalkan antrian, sedangkan balancer berada pada nilai $1,91 /$ detik transaksi.

2) Proses response time atau kecepatan replikasi database dalam menangkap dan mengirimkan data sangat efektif, pada node $10,33 / \mathrm{s}$ untuk kecepatan proses, node 2 dengan waktu 0,01/s, dan balancer $0,13 / \mathrm{s}$.

\section{DAFTAR PUSTAKA}

[1] Balanov Alexander., and Natalia Janson. (2010). Shyncronization : From Simple ToComplex, Springer Series in Synergetics Ser, Dewey edition. Springer. ISBN 9783642091285.

[2] Dix, P. (2010). Service-Oriented Design with Ruby and Rails.(1st edition). Indianapolis: AddisonWesley Professional.

[3] Dollimore, T. Kindberg and G. Blair. (2012). Distributed System Concepts and Design. Boston: Pearson Education, Inc.

[4] Greenwald R., Stackowiak R., \& Stern J. (2008). Oracle Essentials: Oracle Database 11g. (4st edition). Sebastopol: O'Reilly Media, Inc.

[5] Hareendran. (2015). Arduino \& Raspberry Pi Camera interface. www. electroschematics.com.

[6] Kamalapur S., \& Deshpande N. (2008). Distributed Systems.2nd edition. Pune: Technical Publications.

[7] M. T. Ozsu and P. Valduriez. (2006). Principles of Distributed Databases (2nd edition). PrenticeHall: ISBN 0-13-659707-6.

[8] Membrey P., Plugge E., \& Hows D. (2012). Practical Load Balancing: Ride the Performance Tiger. (1st edition). New York: Apress.

[9] Paul Elliott, D. (2004). Spatial Epidemiology: Current Approaches and Future Challenges. Environmental Health Perspectives. 